\title{
The effect of low-dose inhalation of nitric oxide in patients with pulmonary fibrosis
}

\author{
M. Yoshida, O. Taguchi, E.C. Gabazza, H. Yasui, T. Kobayashi, H. Kobayashi, \\ K. Maruyama, Y. Adachi
}

The effect of low-dose inhalation of nitric oxide in patients with pulmonary fibrosis. M. Yoshida, O. Taguchi, E.C. Gabazza, H. Yasui, T. Kobayashi, H. Kobayashi, K. Maruyama, Y. Adachi. @ ERS Journals Ltd 1997.

ABSTRACT: The aim of this study was to determine whether low-dose inhalation of nitric oxide (NO) improves pulmonary haemodynamics and gas exchange in patients with stable idiopathic pulmonary fibrosis (IPF).

The investigation included 10 IPF patients breathing spontaneously. Haemodynamic and blood gas parameters were measured under the following conditions: 1) breathing room air; 2) during inhalation of 2 parts per million (ppm) NO with room air; 3) whilst breathing $\mathrm{O}_{2}$ alone $\left(1 \mathrm{~L} \cdot \mathrm{min}^{-1}\right)$; and 4) during combined inhalation of $2 \mathrm{ppm} \mathrm{NO}$ and $\mathrm{O}_{2}\left(1 \mathrm{~L} \cdot \mathrm{min}^{-1}\right)$.

During inhalation of $2 \mathrm{ppm}$ NO with room air the mean pulmonary arterial pressure $\left(\bar{P}_{\text {pa }} 25 \pm 3\right.$ vs $\left.30 \pm 4 \mathrm{mmHg}\right)$ and the pulmonary vascular resistance (PVR $529 \pm 80$ vs $\left.699 \pm 110 \mathrm{dyn} \cdot \mathrm{s}^{\cdot} \mathrm{cm}^{-5}\right)$ were significantly $(\mathrm{p}<0.01)$ lower than levels measured whilst breathing room air alone. However the arterial oxygen tension $\left(\mathrm{Pa}_{\mathrm{a}} \mathrm{O}_{2}\right)$ did not improve. The combined inhalation of $\mathrm{NO}$ and $\mathrm{O}_{2}$ produced not only a significant $(\mathrm{p}<0.01)$ decrease of $\bar{P}_{\text {pa }}(23 \pm 2$ vs $28 \pm 3 \mathrm{mmHg})$ but also, a remarkable improvement $(\mathrm{p}<0.05)$ in $\mathrm{Pa}_{\mathrm{a}} \mathrm{O}_{2}(14.2 \pm 1.2$ vs $11.7 \pm 1.0 \mathrm{kPa})(107 \pm 9$ vs $88 \pm 7 \mathrm{mmHg})$ as compared with the values observed during the inhalation of $\mathrm{O}_{2}$ alone.

These findings suggest that the combined use of nitric oxide and oxygen might constitute an alternative therapeutic approach for treating idiopathic pulmonary fibrosis patients with pulmonary hypertension. However, further studies must first be carried out to demonstrate the beneficial effect of oxygen therapy on pulmonary haemodynamics and prognosis in patients with idiopathic pulmonary fibrosis and to rule out the potential toxicity of inhaled nitric oxide, particularly when used in combination with oxygen.

Eur Respir J 1997; 10: 2051-2054.
Third Dept of Internal Medicine and Dept of Anesthesiology, Mie University School of Medicine, Tsu-city, Japan.

Correspondence: M. Yoshida

Third Dept of Internal Medicine Mie University School of Medicine

2-174 Edobashi

Tsu-city

Mie prefecture

514 Japan

Keywords: Nitric oxide oxygen

pulmonary fibrosis

Received: February 121997

Accepted after revision July 31997
Idiopathic pulmonary fibrosis (IPF) is characterized by progressive inflammatory and fibrotic processes of the lung [1-3]. The beneficial effect of long-term oxygen therapy (LTOT) has not been demonstrated in IPF patients: however, LTOT is commonly prescribed to patients with advanced IPF associated with hypoxaemia and pulmonary hypertension [4-7]. Inhaled nitric oxide (NO) has been shown to selectively and acutely vasodilate pulmonary vessels in various hypertensive lung diseases [8-11]. Inhaled NO has been shown to be more effective than inhaled oxygen $\left(\mathrm{O}_{2}\right)$ in decreasing the mean pulmonary artery pressure $(\bar{P} \mathrm{pa})$ in disorders associated with chronic pulmonary hypertension [12]. Moreover, inhaled NO improves arterial oxygenation in patients with the acute respiratory distress syndrome (ARDS) undergoing $\mathrm{O}_{2}$ therapy [13].

This effect of inhaled NO has also been demonstrated in cases of pulmonary fibrosis during acute exacerbation undergoing $\mathrm{O}_{2}$ therapy $[14,15]$. CHANNICK et al. [14] first reported that inhalation of 40 parts per million (ppm) NO is effective for improving pulmonary haemodynamics and arterial oxygenation. However, NO concentrations lower than $10 \mathrm{ppm}$ have been shown to be sufficient for improving pulmonary hypertension and gas exchange in ARDS patients [16]. In fact, we have previously reported that 2 ppm NO improved pulmonary hypertension and arterial oxygenation in a patient with IPF undergoing acute exacerbation [15].

However, the effect of inhaled NO in clinically stable IPF patients spontaneously breathing room air has not yet been reported. The combined inhalation of $\mathrm{NO}$ and $\mathrm{O}_{2}$ has been reported to be effective for improving gas exchange and pulmonary haemodynamic parameters in patients with chronic obstructive pulmonary disease (COPD) [17]. We hypothesized that the combined inhalation of $\mathrm{NO}$ and $\mathrm{O}_{2}$ would also be effective for improving oxygenation and pulmonary hypertension in clinically stable IPF patients. The purpose of the present study was to determine whether inhalation of lowdose NO improves pulmonary hypertension and arterial oxygenation in clinically stable IPF patients breathing room air and/or oxygen. 


\section{Methods}

The study included 10 male IPF patients (mean \pm SD age $64 \pm 5$ yrs) breathing spontaneously (table 1 ). The patients were not undergoing acute exacerbation of their disease and did not present any other clinical complication. All patients had restrictive spirometric alterations (vital capacity (VC) $73 \pm 8 \%$ of predicted values; forced expiratory volume in one second/forced vital capacity (FEV1/FVC) 79 $\pm 9 \%$ ), and honeycomb findings on the computed tomographic (CT) scan. Hypoxaemia and pulmonary hypertension were observed in all patients, of whom seven were being treated with LTOT. This latter treatment was stopped about $8 \mathrm{~h}$ before the beginning of the study.

Right heart catheterization was performed with a Swan-Ganz catheter (131H-7F; Baxter Healthcare Co., Irvin, CA, USA) inserted into a basilic vein under local anaesthesia and placed in the pulmonary artery under electrocardiographic and fluoroscopic monitoring. An arterial line was also inserted into a radial artery. Electrocardiogram (ECG), systemic arterial pressure (SAP) and pulmonary artery pressure were monitored continuously. The patients were in supine position. Measurements of haemodynamic parameters and blood gas analysis were carried out under the following conditions: 1) breathing room air; 2) during 2 ppm NO inhalation with room air; 3) after breathing $\mathrm{O}_{2}$ at 1 $\mathrm{L} \cdot \mathrm{min}^{-1}$ through a nasal cannula for $10 \mathrm{~min}$; and 4) during combined inhalation of $2 \mathrm{ppm} \mathrm{NO}$ and $\mathrm{O}_{2}$ at 1 $\mathrm{L} \cdot \mathrm{min}^{-1}$. Nitric oxide was administered for $10 \mathrm{~min} v i a$ a face mask, and this was followed by a resting period of 10-15 min before the next treatment. At the end of each treatment, blood sampling from the radial artery line for blood gas analysis and measurements of the mean pulmonary_capillary wedge pressure $(\bar{P}$ pcw $)$ and cardiac output $\left(Q^{\prime}\right)$ were performed. Cardiac output was measured by the thermodilution method, and pulmonary vascular resistance (PVR) was calculated. Blood gas analyses were carried out using the ABL510 analyser (Radiometer Co., Copenhagen, Denmark).

Nitric oxide mixed in nitrogen at a concentration of 1,000 ppm (Sumitomo Seika Co., Chiba, Japan) was blended with nitrogen using volumetric flow calibrators to obtain the desired level of NO. This diluted $\mathrm{NO} / \mathrm{N}_{2}$ mixture was blended with air using an air compressor (Iwata Co., Tokyo, Japan). This mixture of gas was passed through soda lime to avoid increased nitrogen dioxide $\left(\mathrm{NO}_{2}\right)$ formation, and delivered to the patient through a facial mask. The mask was designed to allow the patient to inspire NO on demand and to exhale expired gas via a wall vacuum. An $\mathrm{NO} / \mathrm{NO}_{2}$ chemiluminescent analyser (APNA-360; Horiba Co., Kyoto, Japan) was connected to an upper inlet of the mask for constant measurement of inspired $\mathrm{NO}$ and to monitor $\mathrm{NO}_{2}$ production. Continuous monitoring of $\mathrm{NO}_{2}$ showed that there was less than $1 \mathrm{ppm}$ of $\mathrm{NO}_{2}$ in the inhaled gas mixture. Following administration to the patient, the gas mixture was collected in a Douglas bag and then discarded.

Informed consent was obtained from each subject enrolled in this investigation. The study was approved by the Ethics Committee of our University and carried out following the principles of the Helsinki Declaration.

\section{Statistical analysis}

Nonparametric two-way analysis of variance (ANOVA) was used for statistical analysis. If the ANOVA test showed statistical significance, the Scheffe test was also performed. All values are expressed as mean \pm SEM. A pvalue of less than 0.05 was considered to be statistically significant.

\section{Results}

The effect of $\mathrm{NO}$ and/or $\mathrm{O}_{2}$ inhalation on pulmonary haemodynamics and gas exchange parameters are presented in table 2. During the inhalation of $2 \mathrm{ppm}$ NO with room air, the $\bar{P}$ pa and PVR were significantly $(\mathrm{p}<0.01)$ lower than those observed while breathing room air only. However, there were not significant changes in the values of $\mathrm{Pa}_{\mathrm{a}} \mathrm{O}_{2}$ and arterial carbon dioxide tension $\left(P \mathrm{a}, \mathrm{CO}_{2}\right)$ during inhalation of $\mathrm{NO}$ with room air, although $\mathrm{Pa}_{\mathrm{a}} \mathrm{O}_{2}$ increased slightly in 5 of the 10 patients.

On the other hand, the values of $\bar{P}_{\text {pa }}$ obtained during inhalation of $2 \mathrm{ppm} \mathrm{NO}$ added to $\mathrm{O}_{2}\left(1 \mathrm{~L} \cdot \mathrm{min}^{-1}\right)$ was

Table 1. - Characteristics of the patients studied

\begin{tabular}{|c|c|c|c|c|c|c|c|c|c|c|c|c|}
\hline \multirow{2}{*}{$\begin{array}{l}\text { Case } \\
\text { No. }\end{array}$} & \multicolumn{2}{|c|}{$\mathrm{VC}$} & \multicolumn{2}{|c|}{ TLC } & \multirow{2}{*}{$\begin{array}{c}\mathrm{FEV}_{1 / \mathrm{FVC}} \\
\%\end{array}$} & \multirow{2}{*}{$\begin{array}{l}{\mathrm{Pa}, \mathrm{O}_{2}}_{\mathrm{kPa}} \\
\mathrm{ka}\end{array}$} & \multirow{2}{*}{$\begin{array}{c}\mathrm{Pa}_{\mathrm{a}, \mathrm{CO}_{2}} \\
\mathrm{kPa}\end{array}$} & \multirow{2}{*}{$\begin{array}{c}\bar{P}_{\mathrm{pa}} \\
\mathrm{mmHg}\end{array}$} & \multirow{2}{*}{$\begin{array}{c}\text { PVR } \\
\text { dyn } \cdot s \cdot \mathrm{cm}^{-5}\end{array}$} & \multirow{2}{*}{$\begin{array}{c}\bar{P}_{\text {pcw }} \\
\mathrm{mmHg}\end{array}$} & \multirow{2}{*}{$\begin{array}{c}\bar{Q}^{\prime} \\
\mathrm{L} \cdot \mathrm{min}^{-1}\end{array}$} & \multirow{2}{*}{$\begin{array}{c}\text { SAP } \\
\mathrm{mmHg}\end{array}$} \\
\hline & $\mathrm{L}$ & $\%$ pred & $\mathrm{L}$ & $\%$ pred & & & & & & & & \\
\hline 1 & 2.4 & 76 & 4.4 & 84 & 68 & 6.1 & 4.4 & 40 & 967 & 4 & 5.2 & 89 \\
\hline 2 & 2.2 & 69 & 3.9 & 76 & 76 & 8.2 & 4.3 & 39 & 845 & 12 & 4.2 & 94 \\
\hline 3 & 1.7 & 56 & 3.4 & 70 & 78 & 7.1 & 4.4 & 49 & 1394 & 10 & 3.8 & 120 \\
\hline 4 & 2.1 & 71 & 3.0 & 71 & 96 & 9.2 & 5.4 & 24 & 536 & 8 & 3.5 & 85 \\
\hline 5 & 2.6 & 69 & 4.3 & 77 & 88 & 8.8 & 6.1 & 20 & 226 & 3 & 5.5 & 83 \\
\hline 6 & 2.5 & 79 & 3.9 & 79 & 75 & 8.4 & 5.6 & 20 & 262 & 11 & 4.1 & 85 \\
\hline 7 & 3.0 & 80 & 5.1 & 88 & 85 & 9.4 & 6.0 & 27 & 567 & 6 & 5.5 & 92 \\
\hline 8 & 2.3 & 73 & 3.9 & 82 & 83 & 8.6 & 5.8 & 20 & 668 & 4 & 2.9 & 89 \\
\hline 9 & 2.3 & 79 & 4.4 & 90 & 72 & 6.0 & 5.0 & 33 & 913 & 9 & 3.1 & 104 \\
\hline 10 & 2.5 & 79 & 5.0 & 90 & 71 & 8.1 & 5.2 & 29 & 620 & 10 & 4.4 & 96 \\
\hline Mean & 2.4 & 73 & 4.2 & 81 & 79 & 8.0 & 5.2 & 30 & 700 & 8 & 4.2 & 94 \\
\hline $\mathrm{SD}$ & 0.3 & 8 & 0.6 & 7 & 9 & 1.2 & 0.7 & 10 & 348 & 3 & 0.9 & 11 \\
\hline
\end{tabular}

VC: vital capacity; TLC: total lung capacity; FEV1/FVC: forced expiratory volume in one second/forced vital capacity; $P a, \mathrm{O}_{2}$ : arterial oxygen tension; $P_{\mathrm{a}}, \mathrm{CO}_{2}$ : arterial carbon dioxide tension; $\bar{P}_{\mathrm{pa}}$ : mean pulmonary arterial pressure; PVR: pulmonary vascular resistance; $\bar{P}_{\text {pcw }}$ : mean pulmonary capillary wedge pressure; $\bar{Q}^{\prime}$ : cardiac output; SAP: mean systemic arterial pressure. $(1 \mathrm{kPa}$ $=7.5006 \mathrm{mmHg}$ ). 
Table 2. - Effect of inhaled nitric oxide (NO) and/or oxygen on pulmonary haemodynamics and gas exchange parameters $(n=10)$

\begin{tabular}{lccccc}
\hline Variables & Room air & $\mathrm{NO}+$ Room air & Oxygen & $\mathrm{NO}+$ Oxygen & p-value \\
\hline $\bar{P}_{\mathrm{pa} \mathrm{mmHg}}$ & $30 \pm 4$ & $25 \pm 3 * *$ & $28 \pm 3$ & $23 \pm 2+4$ & 0.0001 \\
$\mathrm{PVR} \mathrm{dyn} \cdot \mathrm{s} \cdot \mathrm{cm}^{-5}$ & $699 \pm 110$ & $529 \pm 80^{* *}$ & $632 \pm 105$ & $526 \pm 77$ & 0.0001 \\
$\bar{P}_{\mathrm{pcw} \mathrm{mmHg}}$ & $8 \pm 1$ & $8 \pm 1$ & $7 \pm 1$ & $7 \pm 1$ & $\mathrm{NS}$ \\
$\bar{Q}^{\prime} \mathrm{L} \cdot \mathrm{min}^{-1}$ & $4.2 \pm 0.3$ & $4.2 \pm 0.3$ & $4.1 \pm 0.3$ & $4.0 \pm 0.3$ & $\mathrm{NS}$ \\
$\mathrm{SAP} \mathrm{mmHg}$ & $94 \pm 4$ & $93 \pm 3$ & $94 \pm 4$ & $95 \pm 4$ & $\mathrm{NS}$ \\
$P_{\mathrm{a}, \mathrm{O}_{2}} \mathrm{kPa}$ & $8.1 \pm 0.5$ & $8.4 \pm 0.5$ & $11.7 \pm 1.0$ & $14.2 \pm 1.2$ & 0.0001 \\
$P_{\mathrm{a}, \mathrm{CO}_{2}} \mathrm{kPa}$ & $5.1 \pm 0.2$ & $5.2 \pm 0.2$ & $5.1 \pm 0.1$ & $5.2 \pm 0.1$ & $\mathrm{NS}$ \\
\hline
\end{tabular}

Data are presented as mean \pm SEM. NS: nonsignificant. $* *: p<0.01$, compared with values

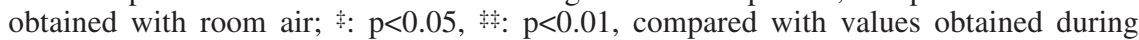
inhalation of oxygen alone. $(1 \mathrm{kPa}=7.5006 \mathrm{mmHg})$. For further definitions see legend to table 1 .

also significantly $(\mathrm{p}<0.01)$ lower than that obtained during inhalation of $\mathrm{O}_{2}$ without NO. Moreover, the values of $\mathrm{Pa}, \mathrm{O}_{2}$ obtained during inhalation of $2 \mathrm{ppm} \mathrm{NO}$ added to $\mathrm{O}_{2}\left(1 \mathrm{~L} \cdot \mathrm{min}^{-1}\right)$ was significantly $(\mathrm{p}<0.05)$ higher than that obtained during inhalation of $\mathrm{O}_{2}\left(1 \mathrm{~L} \cdot \mathrm{min}^{-1}\right)$ without NO. No significant changes were observed in the values of $\bar{Q}^{\prime}$ and $P \mathrm{a}, \mathrm{CO}_{2}$.

\section{Discussion}

The results of this study show that the inhalation of a low concentration of NO (2 ppm) improved the pulmonary haemodynamic variables in clinically stable IPF patients. On the other hand, NO inhalation with room air did not improve arterial oxygenation; on the contrary, $\mathrm{Pa}, \mathrm{O}_{2}$ decreased slightly in 5 of the 10 cases. In contrast, combined inhalation of $\mathrm{NO}$ and oxygen increased $\mathrm{Pa}, \mathrm{O}_{2}$ more significantly than inhalation of oxygen alone in all cases.

These results are in accordance with those reported previously in COPD patients [17]. BARBERA et al. [18] performed NO inhalation in stable COPD patients breathing room air, and found that improvement of pulmonary hypertension is associated with slight deterioration of arterial oxygenation. The explanation for these findings may be as follows: in COPD, the marked imbalance between pulmonary ventilation and blood flow is the main cause of hypoxaemia; the increase of blood flow in the low ventilation/perfusion $\left(V^{\prime} \mathrm{A} / Q^{\prime}\right)$ areas following NO inhalation enhances the mismatch between pulmonary ventilation and blood perfusion, thereby deteriorating oxygenation. By contrast, in ARDS patients, inhaled NO decreased the amount of intrapulmonary shunt, the major determinant of hypoxaemia in these patients, resulting in improvement of hypoxaemia [13]. The physiopathological mechanism by which hypoxaemia occurs in IPF may be similar to that observed in COPD. The main cause of hypoxaemia in IPF patients at rest is the $V^{\prime} \mathrm{A} / Q^{\prime}$ inequality, and in cases where the imbalance is marked, pulmonary gas exchange worsens following NO inhalation. Inhalation of increasing concentrations of NO produces a concomitant increment of the blood flow in the low $V^{\prime} \mathrm{A} / Q^{\prime}$ areas and a decrease in the $\mathrm{Pa}_{\mathrm{a}} \mathrm{O}_{2}$ values.

On the other hand, the current study also showed that the combined inhalation of $\mathrm{NO}$ and $\mathrm{O}_{2}$ improved arterial oxygenation significantly in comparison to inhalation of $\mathrm{O}_{2}$ alone [17]. The latter effect may be explained by the following mechanism: when $\mathrm{NO}$ and $\mathrm{O}_{2}$ are administered simultaneously, the partial pressure of $\mathrm{O}_{2}$ is enhanced in the pulmonary alveolar gas, thus improving the oxygenation of venous blood. Concomitantly, the blood flow is increased by the vasodilatation induced by NO inhalation. This good matching results in an increase in $\mathrm{Pa}, \mathrm{O}_{2}$.

Combined administration of $\mathrm{NO}$ with $\mathrm{O}_{2}$ may be an another alternative therapeutic modality in patients with hypoxaemia and pulmonary hypertension. LTOT is often indicated in cases of IPF with hypoxaemia and in patients with COPD [4, 5]. In COPD patients, LTOT was previously found to decrease pulmonary artery pressure and to improve prognosis [19]. In patients with IPF, however, LTOT was not found to produce similar beneficial effects as in cases with COPD. However, IPF patients clearly benefit symptomatically from $\mathrm{O}_{2}$ therapy. The administration of $\mathrm{O}_{2}$ relieves their shallow and high frequency breathing pattern, which is induced by a reduced lung transfer factor and by vagal reflexes, and thereby reduces the work of breathing. The administration of NO could be also of benefit in patients undergoing LTOT who require a high flow volume of $\mathrm{O}_{2}$. In these cases, the simultaneous administration of a low concentration of NO could reduce the need for higher levels of oxygen flow volume. In addition, NO has been shown to modulate the pulmonary vascular tone by acting as a protective mechanism against pulmonary vasoconstriction and preventing pulmonary vascular remodelling in rats exposed to chronic hypoxia [20].

The above-mentioned data and the results of the present study suggest that the exogenous inhalation of nitric oxide in combination with oxygen may constitute an alternative therapeutic approach to be considered for treating idiopathic pulmonary fibrosis patients with hypoxaemia and pulmonary hypertension. However, further studies must first be carried out, to demonstrate the beneficial effect of long-term oxygen therapy on pulmonary haemodynamics and prognosis in patients with idiopathic pulmonary fibrosis, and to rule out the potential toxicity of inhaled nitric oxide, particularly when used in combination with oxygen.

\section{References}

1. Crystal RG, Fulmer JD, Roberts WC, Moss ML, Line BR, Reynolds HY. Idiopathic pulmonary fibrosis: clinical, histologic, radiographic, physiologic, scintigraphic, cytologic and biochemical aspects. Ann Intern Med 1976; 85: 769-788.

2. Carrington $\mathrm{CB}$, Gaensler EA, Coutu RE, FitzGerald MX, Gupta RG. Natural history and treated course of usual and desquamative interstitial pneumonia. $N$ Engl J Med 1978; 298: 801-809.

3. Turner-Warwick M, Burrows B, Johnson A. Cryptogenic fibrosing alveolitis: clinical features and their influence on survival. Thorax 1980; 35: 171-180.

4. Strom K, Boe J, and the Swedish Society of Chest 
Medicine. Quality assessment and predictors of survival in long-term domiciliary oxygen therapy. Eur Respir $J$ 1991; 4: 50-58.

5. Miyamoto K, Aida A, Nishimura M, Aiba M, Kira S, Kawakami Y, and the Respiratory Failure Research Group in Japan. Gender effect on prognosis of patients receiving long-term home oxygen therapy. Am J Respir Crit Care Med 1995; 152: 972-976.

6. Weitzenblum E, Ehrhart M, Rasaholinjanahary J, Hirth C. Pulmonary hemodynamics in idiopathic pulmonary fibrosis and other interstitial pulmonary diseases. Respiration 1983; 44: 118-127.

7. Harris P, Heath D. The pulmonary vasculature in fibrosis and granulomatous disease of the lung. In: Harris P, Heath D, eds. The Human Pulmonary Circulation. New York, Churchill Livingstone, 1986; pp. 612-623.

8. Frostell C, Fratacci MD, Wain JC, Jones R, Zapol WM. Inhaled nitric oxide: a selective pulmonary vasodilator reversing hypoxic pulmonary vasoconstriction. Circulation 1991; 83: 2038-2047.

9. Pepke-Zaba J, Higenbottam TW, Dinh-Xuan AT, Stone D, Wallwork J. Inhaled nitric oxide as a cause of selective pulmonary vasodilatation in pulmonary hypertension. Lancet 1991; 338: 1173-1174.

10. Roberts JD, Lang P, Bigatello LM, Vlahakes GJ, Zapol WM. Inhaled nitric oxide in congenital heart disease. Circulation 1993; 87: 447-453.

11. Adnot S, Kouyoumdjian C, Defouilloy C, et al. Hemodynamic and gas exchange responses to infusion of acetylcholine and inhalation of nitric oxide in patients with chronic obstructive lung disease and pulmonary hypertension. Am Rev Respir Dis 1993; 148: 310-316.

12. Moinard J, Manier G, Pillet O, Castang Y. Effect of inhaled nitric oxide on hemodynamics and $V^{\prime} \mathrm{A} / Q^{\prime}$ inequalities in patients with chronic obstructive pulmonary disease. Am J Respir Crit Care Med 1994; 149: 1482-1487.
13. Rossaint R, Falke KJ, Lopez F, Slama K, Pison U, Zapol WM. Inhaled nitric oxide for the adult respiratory distress syndrome. N Engl J Med 1993; 328: 399-405.

14. Channick RN, Hoch RC, Newhart JW, Johnson FW, Smith CM. Improvement in pulmonary hypertension and hypoxemia during nitric oxide inhalation in a patient with end-stage pulmonary fibrosis. Am J Respir Crit Care Med 1994; 149: 811-814.

15. Maruyama K, Kobayasi H, Taguchi O, Chikusa H, Muneyuki M. Higher doses of inhaled nitric oxide might be less effective in improving oxygenation in a patient with interstitial pulmonary fibrosis. Anesth Analg 1995; 81: 204-213.

16. Gerlach H, Rossaint R, Pappert D, Falke KJ. Time course and dose-response of nitric oxide inhalation for systemic oxygenation and pulmonary hypertension in patients with adult respiratory distress syndrome. Eur $J$ Clin Invest 1993; 23: 499-502.

17. Yoshida M, Taguchi O, Gabazza EC, et al. Combined inhalation of nitric oxide and oxygen in chronic obstructive pulmonary disease. Am J Respir Crit Care Med 1997; 155: 526-529.

18. Barbera JA, Roger N, Roca J, Rovira I, Higenbottam TW, Rodriguez-Roisin R. Worsening of pulmonary gas exchange with nitric oxide inhalation in chronic obstructive pulmonary disease. Lancet 1996; 347: 436-440.

19. Weitzenblum E, Sautegeau A, Ehrhart M, Mammosser M, Pelletier A. Long-term oxygen therapy can reverse the progression of pulmonary hypertension in patients with chronic obstructive pulmonary disease. Am Rev Respir Dis 1985; 131: 493-498.

20. Kouyoumdjian C, Adnot S, Levame M, Eddahibi S, Bousbaa H, Raffestin B. Continuous inhalation of nitric oxide protects against development of pulmonary hypertension in chronically hypoxic rats. J Clin Invest 1994; 94: 578-584. 